\title{
Overexpression of Thymosin $\beta 4$ Increases Pseudopodia Formation in LNCaP Prostate Cancer Cells
}

\author{
Mai Ito, Kazuhiro Iguchi, Shigeyuki Usui, and Kazuyuki HiRAno* \\ Laboratory of Pharmaceutics, Gifu Pharmaceutical University; 5-6-1 Mitahora-higashi, Gifu, Gifu 502-8585, Japan. \\ Received March 15, 2008; accepted February 20, 2009; published online March 10, 2009
}

\begin{abstract}
Thymosin $\beta 4$, a major G-actin-sequestering protein, is known to be involved in tumor metastasis. In the present study, we found that thymosin $\beta 4$ expression promotes the formation of actin-based pseudopodia-like extensions, associated with cell migration, in human prostate cancer LNCaP cells. Treatment with the phosphatidylinositol 3-kinase (PI3K) inhibitor wortmannin and Cdc42/Rac1/RhoA inhibitor Clostridium difficile toxin B significantly reduced pseudopodia formation in thymosin $\beta 4$-overexpressing LNCaP cells, suggesting that the pseudopodia formation by thymosin $\beta 4$ is probably involved in PI3K and Rho family pathway. We recently reported that thymosin $\beta 4$ expression is upregulated by androgen deprivation in prostate cancer cells. The increase in thymosin $\beta 4$ may be one of the causes of prostate cancer progression after androgen ablation therapy.
\end{abstract}

Key words thymosin $\beta 4$; LNCaP; pseudopodia; migration

Most patients with advanced prostate cancer are candidates for androgen ablation therapy because growth and progression of prostate cancer cells are initially androgen dependent. ${ }^{1,2)}$ Although androgen ablation therapy initially causes tumor regression in $>80 \%$ of cases, prostate cancer eventually progresses from an androgen-dependent to an aggressive androgen-independent state after the therapy, and the prostate cancer in this state is often difficult to cure. $\left.{ }^{2,3}\right)$ One of the reasons why prostate cancer cells after androgen ablation therapy acquire aggressive phenotype is changes occur in the expression of androgen-regulated genes after the therapy. ${ }^{4,5)}$ In our recent study, we found that thymosin $\beta 4$ expression in androgen-sensitive prostate cancer LNCaP cells is elevated in androgen-deprived culture condition. ${ }^{6}$ )

Thymosin $\beta 4$ is a small acidic $4.9-\mathrm{kDa}$ polypeptide widely distributed in human tissues. Thymosin $\beta 4$ functions as a major G-actin sequestering factor that modulates dynamic changes of actin cytoskeleton. ${ }^{7)}$ In addition, thymosin $\beta 4$ is involved in a variety of physiologic and pathologic processes. For example, thymosin $\beta 4$ is known to promote wound healing, tumor metastasis, and angiogenesis. ${ }^{8-10)}$ Overexpression of thymosin $\beta 4$ is detected highly in metastatic cancer cells in human and animal models. ${ }^{11-13)}$ In addition, thymosin $\beta 4$ stimulates cardiac cell migration and survival related to cardiac repair. ${ }^{14)}$ In the present study, we found that thymosin $\beta 4$ expression increases pseudopodia formation related to cell migration and invasion in human prostate LNCaP cells.

\section{MATERIALS AND METHODS}

Materials Wortmannin was purchased from SigmaAldrich Japan K.K. (Tokyo, Japan). Toxin B from Clostridium difficile was from List Biological Laboratories (Campbell, CA, U.S.A.). U0126 was purchased from Wako Pure Chemical (Osaka, Japan). Rapamycin was from Merck Ltd. (Tokyo, Japan).

Cell Culture Human prostate cancer LNCaP cells were from American Type Culture Collection (Rockville, MD, U.S.A.). LNCaP cells were cultured in RPMI-1640 medium containing $10 \%$ fetal calf serum (FCS) under a humidified atmosphere with $5 \% \mathrm{CO}_{2}$ at $37^{\circ} \mathrm{C}$.
Plasmid Constructions Total RNA from LNCaP cells was extracted using TRIzol reagent (Invitrogen, Carlsbad, CA, U.S.A.) then first-strand complementary DNA was synthesized from the total RNA using SuperScript III (Invitrogen) according to the manufacturer's instructions. The cDNA coding region of human thymosin $\beta 4$ was amplified by polymerase chain reaction (PCR) from the cDNA using primers containing restriction sites for $X b a \mathrm{I}$ and HindIII. The sequences of the primers were, sense: 5'-GCTCTAGAATGTCTGACAAACCCGATATG-3'; antisense: 5'-CCAAGCTTTTACGATTCGCCTGCTTGCTT-3'. PCR was performed using PrimeSTAR HS DNA Polymerase (Takara Bio Inc., Otsu, Japan) under the following conditions: 32 cycles of $30 \mathrm{~s}$ at $98^{\circ} \mathrm{C}, 30 \mathrm{~s}$ at $58^{\circ} \mathrm{C}$, and $30 \mathrm{~s}$ at $72^{\circ} \mathrm{C}$. The resulting PCR product was digested with $X b a \mathrm{I}$ and HindIII and inserted into the $X b a \mathrm{I}$ and HindIII sites of a pRK5 mammalian expression vector. The plasmid vector was purified with QIAGEN Plasmid Midi Kit (Qiagen, Hilden, Germany). The entire sequence of the cloned gene was determined by CEQ2000XL (Beckman Coulter, Fullerton, CA, U.S.A.) and confirmed identical to thymosin $\beta 4$ (TMSB4X: accession number NM 021109).

Transfection LNCaP cells $\left(5.5 \times 10^{5}\right.$ cells $)$ were seeded into 60-mm dishes in Dulbecco's modified Eagle's medium (DMEM) containing 10\% FCS without antibiotics. After incubation for $24 \mathrm{~h}$, the cells were transfected with $4.5 \mu \mathrm{g}$ of either an empty vector or an expression vector encoding thymosin $\beta 4$ using Fugene 6 transfection reagent (Roche Diagnostics, Mannheim, Germany).

Reverse Transcriptase Polymerase Chain Reaction (RTPCR) RT-PCR analysis was performed as described previously. ${ }^{6)}$ Total RNA was extracted using TRIzol reagent (Invitrogen) according to the manufacturer's instructions. The extracted total RNA was dissolved in diethylpyrocarbonatetreated water and quantified by measuring the absorbance at $260 \mathrm{~nm}$. Aliquots of $5 \mu \mathrm{g}$ of total RNA were used to synthesize the first-strand complementary DNA with SuperScript III (Invitrogen) and subjected to PCR amplification with the following primers: thymosin $\beta 4$ sense, 5'-CAGACCAGACTTCGCTCGTA-3'; thymosin $\beta 4$ antisense, 5'-GCTTCTCCTGTTCAATCGT-3'; glyceraldehyde-3-phosphate dehy- 
drogenase (GAPDH) sense, 5'-CCAGCAAGAGCACAAGAGGA-3'; GAPDH antisense, 5'-GCAACTGTGAGGAGGGGAGA-3'. The optimal PCR conditions were determined as the amount of amplification product in proportion to that of input RNA. PCR was performed under the following conditions: 26 cycles of $30 \mathrm{~s}$ at $98^{\circ} \mathrm{C}, 30 \mathrm{~s}$ at $58^{\circ} \mathrm{C}$, and $30 \mathrm{~s}$ at $72^{\circ} \mathrm{C}$ for thymosin $\beta 4 ; 21$ cycles of $30 \mathrm{~s}$ at $94{ }^{\circ} \mathrm{C}, 30 \mathrm{~s}$ at $60^{\circ} \mathrm{C}$, and $30 \mathrm{~s}$ at $72^{\circ} \mathrm{C}$ for GAPDH. GAPDH served as internal RNA control to allow comparison of RNA levels among different specimens. After PCR, the reaction products were resolved on $1.5 \%$ agarose gels and visualized with ethidium bromide.

Transwell Chamber Assay In vitro invasion ability of the cells was assayed using a Transwell cell-culture chamber, as described previously with some modifications. ${ }^{15)}$ Briefly, the upper surface of the membrane with an $8.0-\mu \mathrm{m}$ pore size (Becton Dickinson, Franklin Lakes, NJ, U.S.A.) in a cell culture insert was coated with or without $20 \mu \mathrm{g}$ Matrigel dissolved in $100 \mu \mathrm{l}$ of phosphate buffered saline (PBS) and dried at room temperature. Cells suspended in $100 \mu \mathrm{l}$ of DMEM containing $2 \%$ FCS were seeded at a density of $2.5 \times 10^{5}$ cells/well into the cell culture insert and the insert was placed onto a well filled with the same medium containing $10 \%$ FCS in a 24 -well culture plate (Nalge Nunc, Rochester, NY, U.S.A.) and incubated for $48 \mathrm{~h}$ in a $\mathrm{CO}_{2}$ incubator. After incubation, the filters were fixed with $5 \%$ glutaraldehyde and stained with Giemsa's solution (Merck, Darmstadt, Germany). The cells on the lower surface of the membrane of the chamber were counted. Percent invasion was calculated by the number of cells invaded through Matrigel-coated membrane divided by the number of cells migrated through control without Matrigel membrane, multiplied by 100 .

In Vitro Scratch Wound Migration Assay LNCaP cells $\left(6 \times 10^{5}\right.$ cells $)$ were seeded into $35-\mathrm{mm}$ dishes in DMEM containing $10 \%$ FCS without antibiotics. After $24 \mathrm{~h}$, the cells were transfected with $2 \mu \mathrm{g}$ of empty vector or thymosin $\beta 4$ expression vector. The cells were further incubated for $24 \mathrm{~h}$ then wounded with a pipet tip. Photographs were taken with a microscope at $0,12,24,48$, and $72 \mathrm{~h}$ after wounding, and the width of the wound was measured. Migration ratio (\%) was calculated by the width at each hour divided by the width at $0 \mathrm{~h}$, multiplied by 100 . In the case of the study of effect of various inhibitors on the formation of pseudopodia, cells were pretreated with an inhibitor for $24 \mathrm{~h}$ (wortmannin, rapamycin, $\mathrm{U} 0126)$ or $1 \mathrm{~h}$ ( $C$. difficile toxin $\mathrm{B})$ then wounded. Photographs were taken with a microscope at $4 \mathrm{~h}$ after wounding and the number of pseudopodia was counted.

Phalloidin-Staining of F-Actin Twenty-four hours after transfection, the cells were seeded on coverslips at a density of $3 \times 10^{4}$ cells/coverslip and incubated for $24 \mathrm{~h}$. After washing with PBS, the cells were fixed in $2 \%$ paraformaldehyde for $20 \mathrm{~min}$. The fixed cells were made permeable by treatment with $0.1 \%$ Triton $\mathrm{X}-100$ at room temperature for $5 \mathrm{~min}$. The cells were washed thrice with PBS and stained with $0.4 \mu \mathrm{M}$ Phalloidin-Fluorescein isothiocyanate (Sigma-Aldrich Japan K.K., Tokyo, Japan) for $40 \mathrm{~min}$. After washing thrice with PBS, images were obtained by confocal laser scanning microscopy (LSM510, Carl Zeiss, Jena, Germany).

Statistical Analysis Data presented are the mean \pm S.D. values from at least two individual experiments, and each ex- periment was performed in triplicate. Statistical significance of differences among the groups was assessed by one-way analysis of variance followed by Dunnet's test. $p$-values $<0.05$ were considered statistically significant.

\section{RESULTS}

Increased Migration and Invasion of LNCaP Cells Transfected with Thymosin $\beta 4$ We first examined the expression level of thymosin $\beta 4$ in $\mathrm{LNCaP}$ cells transfected with the thymosin $\beta 4$ expression vector or empty vector. RTPCR analysis showed that thymosin $\beta 4$ expression was significantly higher in the cells transfected with thymosin $\beta 4$ expression vector as compared with those transfected with empty vector (Fig. 1A).

To study the effect of increased thymosin $\beta 4$ expression on cell invasion and migration, we performed transwell chamber assay and in vitro scratch wound migration assay. As can be seen in Fig. 1B, invasion of cells transfected with thymosin $\beta 4$ expression vector was about 2.3-fold higher than that of those transfected with empty vector. The migration of cells transfected with thymosin $\beta 4$ expression vector was also apparently higher at all time points compared with that of those transfected with empty vector (Fig. 1D). Representative images of migration assay at $48 \mathrm{~h}$ after transfection are shown in Fig. 1C. The growth rate of thymosin $\beta 4$-transfected cells was not significantly changed (about 1.1 times) compared with that of empty vector-transfected cells as estimated by alamar blue assay, implying that the increased wound healing of these cells is due to their migration increase.

Increased Pseudopodia Formation in Thymosin $\beta 4$ Transfected LNCaP Cells We found that pseudopodialike extensions were formed in cells transfected with thymosin $\beta 4$ expression vector, especially at $4 \mathrm{~h}$ after wound, while those in the control cells were smaller and less numerous (Fig. 2A). The pseudopodia extension in thymosin $\beta 4$ overexpressing-LNCaP cells exhibited a filopodia-like morphology. In addition, LNCaP cells overexpressing thymosin $\beta 4$ tended to have elongated actin-based tails (Fig. 2B). We then examined the effect of various inhibitors on the formation in thymosin $\beta 4$-transfected LNCaP cells to investigate the mechanism. Figure 3 shows that wortmannin (PI3K inhibitor) and $C$. difficile toxin B (Cdc42/Rac1/RhoA inhibitor) but not rapamycin (mTOR inhibitor) and U0126 (Erk inhibitor) significantly decreased the number of pseudopodia. Dead cells were not observed after treatment with wortmannin or toxin $\mathrm{B}$, suggesting that the effects were not due to non-specific toxicity to LNCaP cells. Cdc42/Rac1/RhoA inhibitor $C$. difficile toxin $\mathrm{B}$ also blocked pseudopodia formation.

\section{DISCUSSION}

In this study, we found that thymosin $\beta 4$ overexpressing LNCaP cells increase the formation of actin-based pseudopodia and cell migration. Pseudopodia (filopodia and lamellipodia) determine the direction of cell migration and produce the driving force for cell migration. Therefore induction of pseudopodia formation by thymosin $\beta 4$ seems to be involved in the increase of cell migration.

What is the mechanism by which thymosin $\beta 4$ causes 
(A)

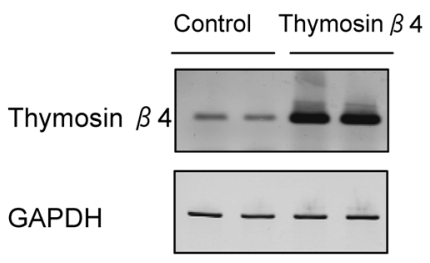

(B)

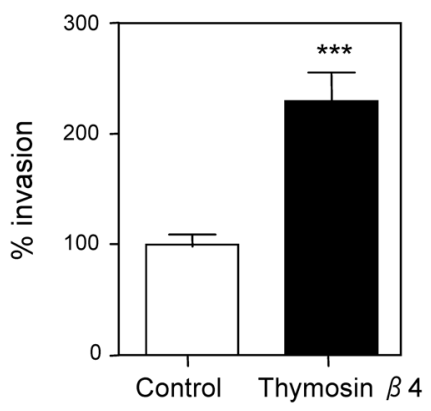

(C)

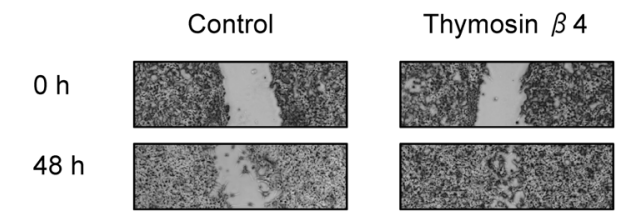

(D)

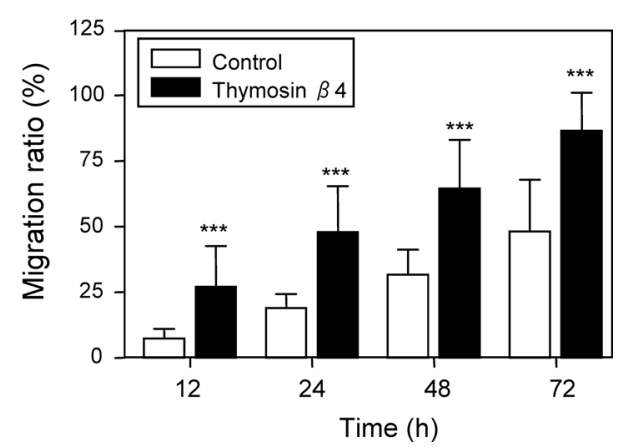

Fig. 1. Invasion and Migration Activities in LNCaP Cells Transfected with Thymosin $\beta 4$ Expression Vector

(A) Overexpression of thymosin $\beta 4$. LNCaP cells were transfected with thymosin $\beta 4$ expression vector or empty vector (control). Total RNA was isolated $24 \mathrm{~h}$ after transfection and thymosin $\beta 4$ mRNA expression was analyzed by RT-PCR. (B) Invasion assay. LNCaP cells were transfected with thymosin $\beta 4$ expression vector or empty vector (control) and incubated for $24 \mathrm{~h}$. The cells were used in Transwell chamber assay as described in Materials and Methods. (C, D) Migration assay. In vitro scratch wound migration assay was performed as described in Materials and Methods. (C) Phase contrast image. (D) Width of the wound was measured at $\geq 6$ different sites. Values represent mean \pm S.D. from at least two independent experiments, each performed in triplicate. $* * * p<0.001$ versus control.

(A)

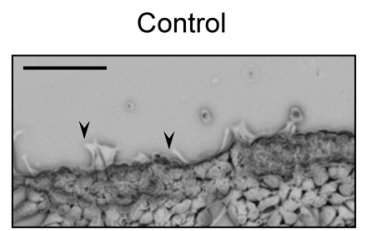

(B)
Control

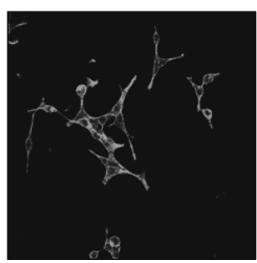

Thymosin $\beta 4$

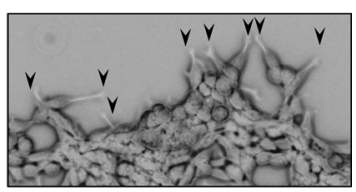

Thymosin $\beta 4$

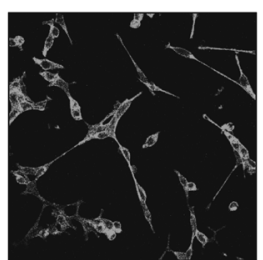

Fig. 2. Pseudopodia Formation in LNCaP Cells Transfected with Thymosin $\beta 4$ Expression Vector

(A) Phase contrast image of in vitro scratch wound migration assay at $4 \mathrm{~h}$ after wound. Arrowhead indicates pseudopodia. Bar $=100 \mu \mathrm{m}$. (B) F-actin staining. The cells were seeded on coverslips and stained F-actin as described in Materials and Methods.

pseudopodia extension? Thymosin $\beta 4$ activates various signaling pathways including integrin-linked kinase (ILK), Jnk1, extracellular signal-regulated kinase (Erk), and c-Jun. ${ }^{14,16)}$ In our study, pseudopodia formation was significantly inhibited by a PI3K inhibitor in thymosin $\beta 4$ overexpressing LNCaP cells. ILK activity is positively regulated by PI3K, which leads to Cdc42 and Rac activation, then pseudopodia formation. In addition, the Rho family inhibitor predictably suppressed pseudopodia formation by thymosin $\beta 4$ overexpression. These observations suggest that one possible explanation for the pseudopodia formation is activation of PI3K

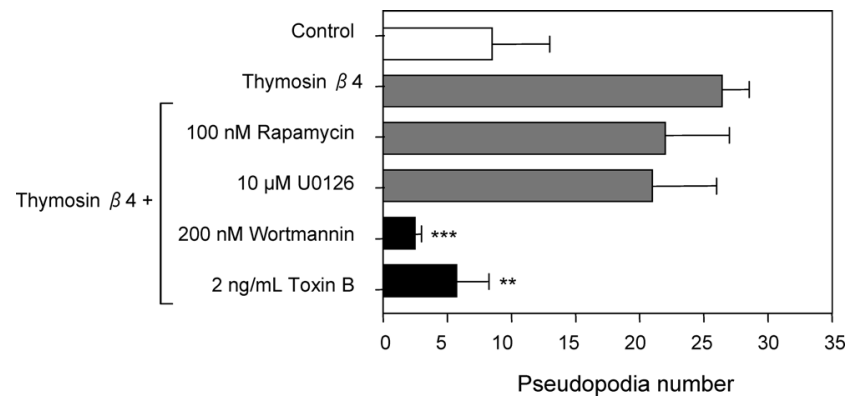

Fig. 3. Effect of Various Inhibitors on Pseudopodia Formation in LNCaP Cells Transfected with Thymosin $\beta 4$ Expression Vector

LNCaP cells were seeded into 35 -mm dishes, transfected with thymosin $\beta 4$ expression vector or empty vector (control), treated with each inhibitor for $24 \mathrm{~h}$ (wortmannin, rapamycin, U0126) or $1 \mathrm{~h}$ (Clostridium difficile toxin B), and then wounded. All spikes of the cell leading edge were counted as pseudopodia. The number of pseudopodia was counted at $\geq 6$ different sites. Values represent mean \pm S.D. from at least two independent experiments, each performed in triplicate. $* * p<0.01$, *** $p<0.001$ versus thy$\operatorname{mosin} \beta 4$.

signaling pathway by thymosin $\beta 4$.

Thymosin $\beta 4$ is known to be released from cells. ${ }^{17,18)}$ It is not clear whether the pseudopodia induction in thymosin $\beta 4$ overexpressing $\mathrm{LNCaP}$ cells was mediated intracellulary and/or extracellulary. We have a preliminary result showing that cells with pseudopodia are different from those transfected with thymosin $\beta 4$ expression vector, estimated by cotransfection with a plasmid expressing enhanced green fluorescent protein (pEGFP-N1) (data not shown). This suggests that the effect of thymosin $\beta 4$ on pseudopodium formation may be cell non-autonomous.

There are several studies that demonstrate increased activity of cell invasion and migration by thymosin $\beta 4$. For instance, thymosin $\beta 4$ overexpressing mouse fibrosarcoma 
cells have been reported to increase migration potential in vitro and tumorigenicity and metastatic potential in vivo. ${ }^{9}$ Overexpression of thymosin $\beta 4$ in SW480 colon carcinoma cells has been shown to result in increased migration with enhanced focal adhesion. ${ }^{19,20)}$ Moreover, thymosin $\beta 4$ treatment has been revealed to increase motility of cardiac cells and endothelial cells, and the stimulated cell migration is caused by upregulation of ILK and Akt activities. ${ }^{14,21)}$ In this study with LNCaP cells transfected with thymosin $\beta 4$ expression vector, it was confirmed that invasion and migration abilities were increased by thymosin $\beta 4$.

In summary, increased expression of thymosin $\beta 4$ results in pseudopodia formation, associated with cell migration in prostate cancer LNCaP cells. We have recently reported that thymosin $\beta 4$ expression is negatively regulated by androgen. The elevated thymosin $\beta 4$ expression may be one possible cause for increased prostate tumor metastasis after androgen ablation therapy.

\section{REFERENCES}

1) Huggins C., Hodges C. V., Cancer Res., 1, 293-297 (1941).

2) Isaacs J. T., BJU Int., 96, 35-40 (2005).

3) Emmett J. L., Greene L. F., Papantoniou A., J. Urol., 83, 471-484 (1960).

4) Holzbeierlein J., Lal P., LaTulippe E., Smith A., Satagopan J., Zhang L., Ryan C., Smith S., Scher H., Scardino P., Reuter V., Gerald W. L., Am. J. Pathol., 164, 217-227 (2004).

5) Kleeberger W., Bova G. S., Nielsen M. E., Herawi M., Chuang A. Y., Epstein J. I., Berman D. M., Cancer Res., 67, 9199_9206 (2007).
6) Iguchi K., Ito M., Usui S., Mizokami A., Namiki M., Hirano K., J. Androl., 29, 207-212 (2008).

7) Safer D., Elzinga M., Nachmias V. T., J. Biol. Chem., 266, 4029-4032 (1991).

8) Sosne G., Chan C. C., Thai K., Kennedy M., Szliter E. A., Hazlett L. D., Kleinman H. K., Exp. Eye Res., 72, 605-608 (2001).

9) Kobayashi T., Okada F., Fujii N., Tomita N., Ito S., Tazawa H., Aoyama T., Choi S. K., Shibata T., Fujita H., Hosokawa M., Am. J. Pathol., 160, 869-882 (2002).

10) Cha H. J., Jeong M. J., Kleinman H. K., J. Natl. Cancer Inst., 95, 1674-1680 (2003).

11) Yamamoto T., Gotoh M., Kitajima M., Hirohashi S., Biochem. Biophys. Res. Commun., 193, 706-710 (1993).

12) Clark E. A., Golub T. R., Lander E. S., Hynes R. O., Nature (London), 406, 532-535 (2000).

13) Vigneswaran N., Wu J., Sacks P., Gilcrease M., Zacharias W., J. Oral Pathol. Med., 34, 77-86 (2005).

14) Bock-Marquette I., Saxena A., White M. D., Dimaio J. M., Srivastava D., Nature (London), 432, 466-472 (2004).

15) Ishii K., Usui S., Sugimura Y., Yoshida S., Hioki T., Tatematsu M., Yamamoto H., Hirano K., Int. J. Cancer, 92, 49-54 (2001).

16) Al-Nedawi K. N., Czyz M., Bednarek R., Szemraj J., Swiatkowska M., Cierniewska-Cieslak A., Wyczolkowska J., Cierniewski C. S., Blood, 103, 1319-1324 (2004).

17) Frohm M, Gunne H, Bergman A. C., Agerberth B., Bergman T., Boman A., Lidén S., Jörnvall H., Boman H. G., Eur. J. Biochem., 237, 86-92 (1996)

18) Huang W. Q., Wang Q. R., Exp. Hematol., 29, 12-18 (2001).

19) Wang W. S., Chen P. M., Hsiao H. L., Ju S. Y., Su Y., Oncogene, 22, 3297-3306 (2003)

20) Wang W. S., Chen P. M., Hsiao H. L., Wang H. S., Liang W. Y., Su Y., Oncogene, 23, 6666-6671 (2004).

21) Huang H. C., Hu C. H., Tang M. C., Wang W. S., Chen P. M., Su Y., Oncogene, 26, 2781-2790 (2007) 